\title{
Seawater copper content controls biofilm bioaccumulation and microbial community on microplastics
}

Kahina Djaoudi ${ }^{1,2}$, Javier Tesan', Amine Boukra' ${ }^{1}$, Lucas Guesnay ${ }^{3}$, Aurélie Portas ${ }^{3}$, Raphaëlle Barry-Martinet ${ }^{3}$, Bernard Angeletti ${ }^{4}$, Stéphane Mounier', Véronique Lenoble ${ }^{1}$, Jean-François Briand ${ }^{3}$.

. Université de Toulon, Aix Marseille Univ., CNRS/INSU, IRD, MIO UM 110, Mediterranean Institute of Oceanography, CS 60584, 83041 - Toulon, France

2 Department of Molecular and Cellular Biology, University of Arizona, Tucson, Arizona, 85721, USA.

${ }^{3}$ Laboratoire MAPIEM, EA 4323, Université de Toulon, Toulon, France

" Aix Marseille Univ, CNRS, IRD, INRA, Coll France, CEREGE, Aix-en-Provence, France

Corresponding author: kdjaoudi@email.arizona.edu

briand@univ-tln.fr 


\begin{abstract}
The understanding of the interactions between trace metals and microplastics (MPs) is hampered by the poorly understood role of biofilm in trace metal bioaccumulation. In this study, the influence of seawater copper content on biofilm microbial communities' composition as well as on the resulting $\mathrm{Cu}$ biofilm bioaccumulation on MPs was investigated within seawater of Toulon-bay (NW Mediterranean Sea), highly impacted by anthropogenic pollution. Based on incubation experiments, the bioaccumulation of copper $(\mathrm{Cu})$ was examined following an increasing gradient of its concentrations. Two sets of incubation experiments were run with seawater supplied with MPs, sampled in two sites in which $\mathrm{Cu}$ contents differed: Pt12 (most contaminated site) and Pt41P (less contaminated site). For each incubation experiment, 5 treatments were considered differing in $\mathrm{Cu}$ concentrations, ranging between 30 and $400 \mathrm{nM}$ and between 6 and 60 $\mathrm{nM}$, for Pt12 and Pt41p, respectively. A control experiment (filtered at 0.2 $\mu \mathrm{m})$ was run in parallel for each incubation experiment. At the time scale of the incubation period, both prokaryotic and eukaryotic richness and diversity of the formed biofilm onto MPs was higher in the more contaminated site, thus appearing as the most driving factor. In addition, $\mathrm{Cu}$ addition clearly shaped biofilm communities, evidencing co-occurrence patterns between prokaryotes and eukaryotes with diatoms playing a central role. Remarkably, these differences in biofilm formation were reflected in the amount of bioaccumulated $\mathrm{Cu}$ per dry weight of MPs, thus exhibiting higher values in the most contaminated site. Within this site, the increase of $\mathrm{Cu}$ seawater content enhanced its bioaccumulation onto MPs until reaching saturation. This study strongly suggests a striking link between seawater copper content, biofilm community shaping and the resulting $\mathrm{Cu}$ bioaccumulation onto MPs.
\end{abstract}


Keywords: Microplastics; bioconcentration; copper; microbial community composition; biofilm.

\section{Introduction}

Over the last few decades, plastic debris of the millimetre size range (<5 mm), identified as microplastics (MPs) (Derraik, 2002; Andrady, 2011, Law, 2017), have become of an increasing concern due to their prevalence within the water column (114 studies performed in the last 20 years; Aretoulaki et al., 2020), impact on ecosystems (Huang et al., 2020; Khalid et al., 2020) and their potential to sorb chemical contaminants (Holmes et al., 2012; Turner and Holmes, 2015; Brennecke et al., 2016; Acosta-Coley et al., 2019). Hydrophobic organic pollutants have been highlighted as being incorporated into MPs and/or adsorbed onto their surface (Fossi et al., 2012; Antunes et al., 2013). In contrast, sorption of trace metals (TMs) on MPs as well as their incorporation into these artificial particles have been shown as limited (Klöckner et al., 2020; Zou et al., 2020).

Nevertheless, these reported studies on TMs sorption/incorporation were performed on pristine MPs, therefore on polymer matrices devoid of any biological colonization. However, MPs are clearly suitable for biofilm formation as they were shown to host a diverse microbial community, including heterotrophs, autotrophs, predators and symbionts, referred to as 'a plastisphere' (Zettler et al., 2013; Amaral-Zettler et al., 2020). Because biofilms are typically built up by a complex matrix of extracellular polymeric compounds, it is very likely that its formation on MPs could increase and 
modify the exchange surface of these synthetic particles within the water column, which would potentially influence the interaction with TMs. Therefore, TMs load on MPs should be looked at whilst considering the role of biofilm in this accumulation. So far, to the best of our knowledge, only few studies involving MPs, biofilm and metals were conducted, thus revealing a higher metal sorption when comparing MPs as pristine versus colonized by biofilm (Guan et al., 2020). Recently, metal accumulation has been shown to correlate with the amount of biofilm (Richard et al., 2019). Although evidence emerged supporting the role of biofilm in enhancing the adsorption and stabilization of trace metal on MPs (Wang et al., 2020), the magnitude of their bioconcentration on MPs as well as the feedback influence on its microbial community composition is still poorly known.

Toulon bay is a coastal marine ecosystem in the NW Mediterranean Sea (South of France), representative of an area coping with anthropogenic metallic pollutants mainly attributed to an important anthropization and extensive harbours activities. Concentrations of TMs in Toulon-bay have been reported as being of the same order of magnitude or even higher than strongly impacted aquatic ecosystems (Pringault et al., 2012; Misson et al., 2016), with a decreasing gradient from the most anthropized parts to the open waters of the Mediterranean Sea. Along this gradient, bacterioplankton composition is shaped, including shifting the autotrophic community from picoeukaryote dominated community in the most contaminated parts to cyanobacteria (more representative of the open ocean) in less impacted areas (Coclet et al., 2018, 2019, 2020). Alongside TMs pollution, an important amount of MPs can be found in the surface water of Toulon bay, with an average of $32800 \mathrm{MPs} / \mathrm{km}^{-2}$ (Tesan-Onrubia et al; 2021). Potential bioaccumulation of TMs on MPs may also influence microbial biofilm diversity. Recently, biofilm formation on plastics panels did not appear to be mainly driven by seawater TMs content (Coclet et al., 2021, Catao et al., 2021a), despite strong evidence of the influence of $\mathrm{Cu}$ on 
other biofilm communities (Catao et al., 2019, 2021b). However, in the Toulon-bay as well as in other coastal areas, a better understanding of the interactions of MPs-TMs is critical as MPs are most likely to be ingested by marine organisms and potentially transferred to high trophic levels though the trophic network (Andray, 2011).

In this study, incubation experiments with natural seawater were conducted to investigate the relationship between an increasing range of seawater $\mathrm{Cu}$ content and biofilm formation MPs, its composition including both prokaryotes and eukaryotes, and its role in $\mathrm{Cu}$ bioaccumulation.

\section{Methods}

\subsection{Seawater sampling and bioassay experiments}

In this study, two sets of incubation experiments were carried out with surface seawater sampled into 10-L LDPE carboys at two locations in the bay of Toulon, Pt12 $\left(43.11^{\circ} \mathrm{N} ; 5.93^{\circ} \mathrm{E}\right)$ and $\operatorname{Pt} 41 \mathrm{p}\left(43.26^{\circ} \mathrm{N} ; 6.58^{\circ} \mathrm{E}\right)$ (Fig. 1). Sampled seawater was then filtered in situ, through $90 \mu \mathrm{m}$ mesh plankton net and homogeneously distributed once in the laboratory, into $1 \mathrm{~L}$ ultraclean PFA bottles, under a laminar flow hood. Experimental sampling and incubation bottles were previously washed three times with Milli-Q water (18.2 $\mathrm{M} \Omega$, Millipore), then with $10 \%(\mathrm{v} / \mathrm{v})$ nitric acid $\left(\mathrm{HNO}_{3}\right.$, Analytical Grade, Fisher), rinsed three times with Milli-Q water then filled with Milli-Q water acidified with $0.1 \% \mathrm{HNO}_{3}$ Trace Metal Grade (Fluka). For all experiments, PFA bottles were chosen so as to prevent any metallic contamination.

The sampling locations were chosen based on the long-time monitoring of trace metals performed in the area, highlighting contrasted $\mathrm{Cu}$ concentrations in the considered locations (Tessier et al., 2011, Layglon et al., 2020; Coclet et al., 2018, 2019, 2020). Pt12 sampling station is located in the enclosed part of the bay of Toulon, near the main harbour, 
therefore submitted to important metallic inputs from the anthropogenic activities (Fig. 1). In contrast, Pt41p sampling station is located in the large bay of Toulon, with trace metal concentrations similar to the encountered values in the Mediterranean Sea. In both sampling stations, subsamples were taken for in situ measurements of $\mathrm{Cu}$ and exhibited concentration of $30 \mathrm{nM}$ for Pt12 and $6 \mathrm{nM}$ and Pt41p.

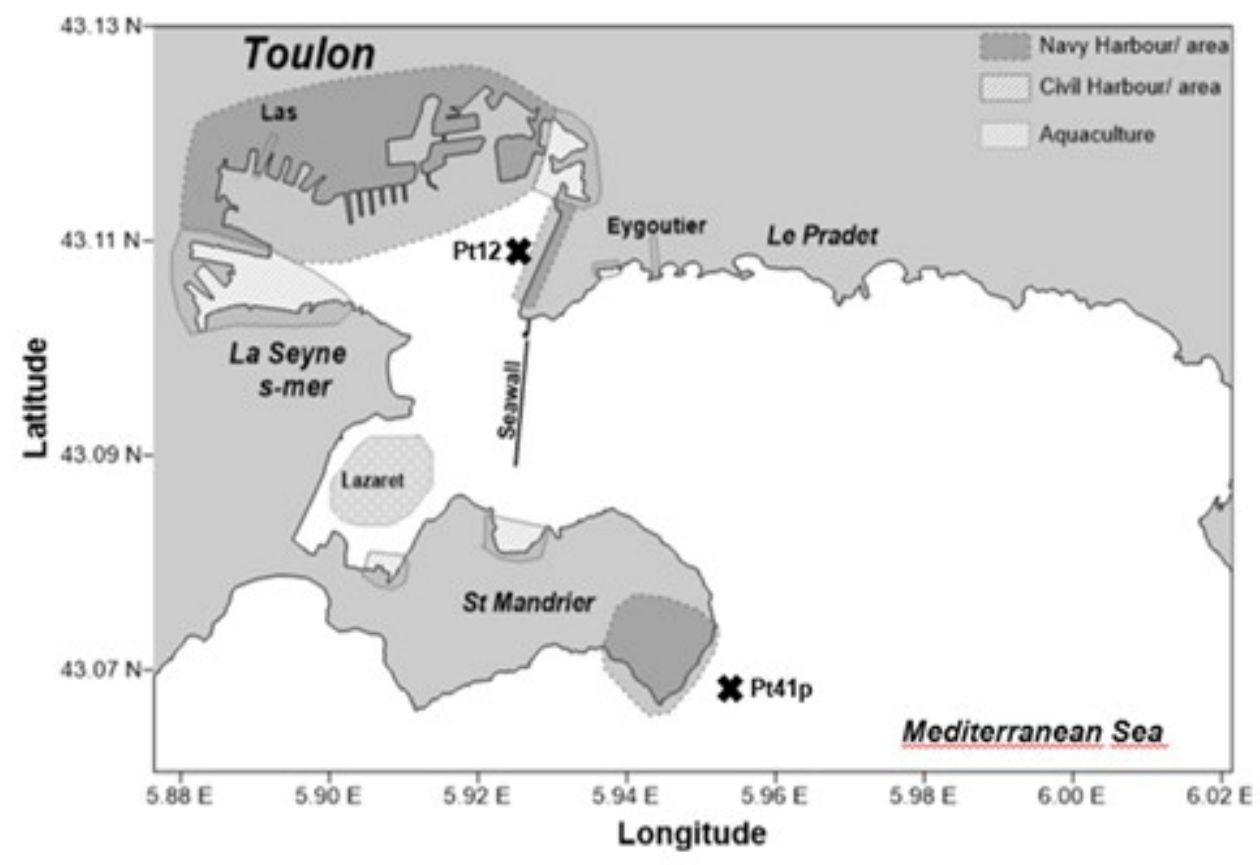

Figure 1: Sampling stations in the small (Pt12) and large (Pt41p) bay of Toulon.

The MPs pellets used in this study were obtained by flash freezing of polymeric polyethylene microbeads (CRT102,50, Carat) in liquid nitrogen and their subsequent grinding, using an ultra-centrifugal mill (ZM200, Retsch). Obtained grinded pellets were further sieved from 500 to $100 \mu \mathrm{m}$ and were thoroughly rinsed with Milli-Q water. MPs were then dried ( $1 \mathrm{~h}$, $60^{\circ} \mathrm{C}$ ) and pellets within a size range between 200 and $300 \mu \mathrm{m}$ were further used. 
The two sets of experiments were run in triplicates (1-L each). Seawater from Pt12 or Pt41p was incubated with a single density of MPs (10 $\mathrm{mg} \mathrm{L}^{-1}$ ) and an increasing gradient of $\mathrm{Cu}$ concentrations. Two ranges of $\mathrm{Cu}$ concentrations were applied whether the seawater was sampled in Pt12 or Pt41p as the initial natural $\mathrm{Cu}$ concentrations differed: 30 and $6 \mathrm{nM}$ in Pt12 and Pt41p, respectively. Thereby, $\mathrm{Cu}$ was added to reach final concentrations of $60,100,200$ and $400 \mathrm{nM}$ in the seawater sampled at Pt12 (hereafter, small bay experiment) and of 20, 30 and $60 \mathrm{nM}$ in the seawater sampled at Pt41p (hereafter, large bay experiment). For each sampling station, a triplicate without any $\mathrm{Cu}$ addition (reflecting in situ concentration), was run in parallel. Likewise, two bottles of 1-L of sterile (filtered at $0.2 \mu \mathrm{m}$, precleaned acetate filters) seawater amended with 10 $\mathrm{mg} \mathrm{L} \mathrm{L}^{-1} \mathrm{MPs}$ and a $\mathrm{Cu}$ concentration of $200 \mathrm{nM}$ and $60 \mathrm{nM}$ for seawater of Pt12 and Pt41p, respectively, were also run as controls. All experimental bottles were gently mixed, using PFA stirring bars and were incubated over 13 days at $18^{\circ} \mathrm{C}$, in a phytotron (Mlr 351 Sanyo) with a day night cycle of $12: 12 \mathrm{~h}$.

\subsection{Subsampling over the incubation period}

Incubated seawater was subsampled at T0 $(1 \mathrm{~h}$ after MPs and $\mathrm{Cu}$ amendment), an intermediate time (T7 or 8), and at Tfinal (after 13 days of incubation period) for bacterioplankton cell abundance and only at Tfinal for $\mathrm{Cu}$. Subsamples for $\mathrm{Cu}(10 \mathrm{~mL})$ were filtered through $0.2 \mu \mathrm{m}$ precleaned acetate syringe filters ( $\mathrm{HCl}$, trace metal grade), acidified with $0.5 \% \mathrm{HCl}$ (trace metal grade) and stored at $4^{\circ} \mathrm{C}$ until analysis. Subsamples for heterotrophic and autotrophic cell abundance determination were fixed with 0.5\% glutaraldehyde (final concentration), incubated in the dark for $15 \mathrm{~min}$ at ambient temperature and then transferred into $-80^{\circ} \mathrm{C}$ freezer, until analysis. Unfiltered seawater $(10 \mathrm{~mL})$ was subsampled at the same time scale for both heterotrophic and autotrophic bacterioplankton cell abundance. These samples were fixed with $0.5 \%$ glutaraldehyde (final 
concentration), incubated in the dark for $15 \mathrm{~min}$ at ambient temperature and then transferred into $-80^{\circ} \mathrm{C}$ freezer, until analysis.

At the end of the incubation period, for all experiments, each incubation bottle was filtered through $0.2 \mu \mathrm{m}$ polycarbonate filters $(\mathrm{HCl}$ washed, trace metal grade) to recover MPs. Half of the recovered MPs was used for biofilm diversity determination, through DNA extraction while the other half was suspended in $10 \mathrm{~mL} \mathrm{NaOH}(0.1 \mathrm{M})$ and mixed up for $24 \mathrm{~h}$, for biofilm extraction. A few randomly chosen pellets were also fixed for biofilm visualization using confocal laser scanning microscopy (CLSM).

\subsection{DNA extraction, amplification, sequencing, and data processing}

DNA from MPs was extracted using the DNeasy PowerBiofilm Kit (Qiagen, Courtaboeuf, France) according to the manufacturer's instructions. For all samples, the V4-V5 region of the 16S rDNA gene was targeted and amplified using 515F-Y/926R primers (Parada et al., 2016) for prokaryotes identification whereas the $18 \mathrm{~S}$ rDNA gene was targeted and amplified using V7 primers (Debroas et al., 2017) for eukaryotes identification. Amplicons were sent to Eurofins (Konstanz, Germany) for Illumina MiSeq $2 \times 300 \mathrm{pb}$ paired-end sequencing.

Sequences were analysed following the FROGS process (Escudié et al., 2018) in a Galaxy environment following current guidelines. Clustering relies on Swarm which does not agglomerate sequences based on the typical $97 \%$ threshold but relies instead on both the number of differences and the likely series of accumulation of those differences (Mahé et al., 2014). Chimera detection relies on VSEARCH with de novo UCHIME method (Edgar et al., 2011; Rognes et al., 2016). The innovative crosssample validation step from FROGS was used to confirm the chimeric status on all samples. Rare OTUs representing less than $0.005 \%$ of all sequences were removed. Affiliation by blastn+ was performed using the SILVA v132 
database for prokaryotes and the Protist Ribosomal 2 (PR2) database (Guillou et al., 2012) for eukaryotes. The datasets for this study can be found in NCBI SRA database, Bioproject PRJNA735079.

\subsection{Confocal laser scanning microscopy (CLSM) and Scanning Electron microscopy (SEM)}

MPs were washed in artificial seawater and subsequently fixed with $3.8 \%$ formaldehyde solution. To visualize cells, staining was performed with $250 \mu \mathrm{l}$ of Syto 9 or Syto 61 (1 $\mu \mathrm{M}$-ThermoFisher) in 24-well plates for $30 \mathrm{~min}$, in the dark and at room temperature. In addition, exopolymeric substances (EPS) characterizing biofilm development were also visualized using FITC (proteins), concanavalin A (ConA, sugar) and calcofluor white (CFW, sugar). After 2 washes in phosphate buffered saline solution, microplastics were mounted on microscope slices with one drop of Prolong Diamond antifade (ThermoFisher) and incubated for 24 hours at room temperature. Confocal images were performed with 20X/0.75NA and 63xoil/1.4NA objectives, on a Zeiss Confocal LSM 510 Meta (excitation: 488 nm - emission: BP 505-530 $\mathrm{nm})$.

\subsection{Copper extraction and analysis}

$\mathrm{NaOH}$ mixtures were filtered $(0.2 \mu \mathrm{m})$ and the retained MPs were dried and then weighed. A volume of $5 \mathrm{~mL}$ of the filtered $\mathrm{NaOH}$ mixture was taken and completed to $10 \mathrm{~mL}$ with filtered Milli-Q water (18.2 $\mathrm{M} \Omega$, Millipore). Then, the solution (10 mL) was UV-irradiated (Metrohm) for $24 \mathrm{~h}$ in presence of $\mathrm{H}_{2} \mathrm{O}_{2}$, to ensure a complete digestion of the extracted biofilm. The solution was finally analysed for $\mathrm{Cu}$ concentration.

$\mathrm{Cu}$ analyses were performed by cell-inductively coupled plasma mass spectrometry (ICP-MS; Perkin Elmer NexIon 300X), in a direct injection mode. The international geostandards SLRS-3 (Riverine water reference material) was used to check the validity and reproducibility of the analysis. 
To avoid interference with seawater salt, incubation bottle samples were diluted 25 times in nitric acid, while extracted biofilm samples were diluted only 5 times. With obtained $\mathrm{Cu}$ concentrations in the incubation bottle ( $\mathrm{T}=13$ days) and in the extracted biofilm, the partition coefficient $(\mathrm{Kd})$ was determined as follow:

$$
\mathrm{Kd}(\mathrm{L} / \mathrm{Kg})=([\mathrm{Cu}] \text { Biofilm } / \mathrm{MPs} \text { mass }) /[\mathrm{Cu}] \text { final }
$$

Where $\mathrm{Cu}$ biofilm and $\mathrm{Cu}$ final are $\mathrm{Cu}$ concentrations in the extracted biofilm solution and in incubated water after 13 days of incubation time, respectively. MPs mass is the dry weight of MPs.

\subsection{Flow cytometry analyses}

Cell abundance counting was performed using a FACSCalibur (BD Biosciences) flow cytometer (PRECYM flow cytometry platform, http://precym.mio.univ-amu.fr/). Instrument specific beads were used to calibrate the cytometer. For heterotrophic bacteria, frozen samples were thawed at room temperature and subsamples were stained with 1:10 diluted SYBR Green II ( $2 \mu \mathrm{L}$, Molecular Probes) and incubated for $15 \mathrm{~min}$ in the dark, in order to stain nucleic acids. Each cell was then characterized by 3 optical parameters: light diffusion side scatter (SSC); green fluorescence (515-545 nm; SYBERgreen), and red fluorescence (670 LP; chlorophyll-a). Group-specific phytoplankton were distinguished based on plots of forward scatter vs. orange fluorescence (phycoerythrin containing Synechococcus like), and forward scatter vs. red fluorescence (eukaryotes). Size classes of

eukaryotic phytoplankton were further distinguished based on forward scatter (pico, nano and large eukaryotes). Flow cytometry data were acquired and counted with the Cell Quest Pro software.

\subsection{Statistical analysis}


$\mathrm{Cu}$ concentrations in the incubation bottles as well as in the extracted biofilm, $\mathrm{Kd}$ and alpha diversity indexes were compared using a one-way analysis of variance (ANOVA) and Tuckey posthoc tests ( $p$-value $>5 \%$ ).

Alpha diversity indexes (Chao 1, Shannon), clustering using Weighted Unifrac distances (Prokaryotes) and Unweighted Unifrac distances (Eukaryotes) followed by Principal Coordinates Analysis (PCoA) and PERMANOVA were performed using $\mathrm{R}$ Cran version (3.5.0.4) with "phyloseq", "vegan" and "ggplot" program packages. The approach taking only into account the presence or absence of eukaryotic taxa, in addition to phylogenetic distances, was considered appropriate to account for possible biases associated with the limited quantification capacity of eukaryotic metabarcoding (Kelly et al. 2014). SIMPER analyses were performed to precise the contributors to the dissimilarity between pairs of samples (PRIMER•6).

Interactions among prokaryotic and eukaryotic OTUs were identified using CoNeT (Co-occurrence Network) plugin 1.1.1.beta (Faust et al., 2012). Data were processed using Pearson and Spearman correlation, with

Bray-Curtis and Kullback-Leiber dissimilarity distances and using a threshold of 150 and 400 edges for Pt12 and Pt41p, respectively. Edge specific p-values were computed according to Brown's method, in the permutation step. In the final step, the Benjamini-Hochberg multiple testing correction was applied $(\mathrm{p}<0.05)$.

\section{Results}

\subsection{Influence of $\mathrm{Cu}$ seawater content on pico- and nanoplankton cell abundance within the incubation experiments}

One hour after $\mathrm{Cu}$ amendments (T0), picophytoplankton composition in seawater from Pt12 (Fig. S1-a) was dominated by picoeukaryotes (between $6000 \pm 427$ and $11000 \pm 364$ cells $\mathrm{mL}^{-1}$ ), followed by 
Prochlorococcus-like (between $508 \pm 12$ and $1630 \pm 158$ cells $\mathrm{mL}^{-1}$ ) and Synechococcus-like (between $45 \pm 4$ and $603 \pm 40$ ), in all considered treatments. Following the increasing gradient of $\mathrm{Cu}$ (from 30 to $400 \mathrm{nM}$ ), the initial cell abundance of each group significantly decreased (ANOVA; $p<0.01$ ). After 13 days of incubation (for each experiment, bars on the right, Fig. S1-a), Synechococcus-like disappeared while both picoeukaryotes and Prochlorococcus-like drastically decreased (ANOVA; $p<0.01)$, particularly in treatments with the highest levels of $\mathrm{Cu}$. Initial nanophytoplankton cell abundance (for each experiment, bars on the left, Fig. S1-c) in Pt12 exhibited a decrease with the increase in $\mathrm{Cu}$ gradient. After 13 days of incubation, nanophytoplankton cells abundance significantly increased (ANOVA; $p<0.01$ ) compared to T0, in treatments having received 30 and 60 $\mathrm{nM}$ of $\mathrm{Cu}$, remained constant with amendments of 100 and $200 \mathrm{nM}$ of $\mathrm{Cu}$ (ANOVA; $p>0.05$ ) and decreased in the treatment with $400 \mathrm{nM}$ of $\mathrm{Cu}$ (ANOVA; $p<0.01$ ). Regarding heterotrophic bacteria (Fig. S1-e), initial cell abundance was not influenced by the increasing $\mathrm{Cu}$ gradient. On the contrary, after 13 days of incubation time, cell abundance significantly decreased in each treatment (ANOVA; $\mathrm{p}<0.01$ ). Nevertheless, following the increase in $\mathrm{Cu}$ concentration, an increase in final cell abundance ( $\mathrm{T}=13$ days) was observed, except in the treatment with $400 \mathrm{nM}($ ANOVA; $\mathrm{p}<0.01$ ) (Fig. S1).

In seawater from Pt41p (large bay of Toulon), initial picophytoplankton abundances were higher than at Pt12 (Fig. S1-b) and the composition here was dominated by Synechococcus-like, followed by Prochlorococcus-like and finally picoeukaryotes (ANOVA; $p<0.01$ ), in each treatment. As for seawater from Pt12, after 13 days of incubation period, cell abundance dropped in all treatments (ANOVA; $p<0.01)$, within each group. This decrease was more pronounced for treatments with the highest $\mathrm{Cu}$ concentrations. The initial nanoplankton cell abundance was, conversely to picophytoplankton, lower at Pt41p than at Pt12 (Fig. S1-b). Initial cell 
abundance significantly decreased in treatments with 30 and $60 \mathrm{nM}$ of $\mathrm{Cu}$ (ANOVA; $p<0.01$ ). After 13 days of incubation time, the nanoplankton abundance trend was not clear. Regarding heterotrophic bacteria (Fig. S1f), the initial cell abundance remained similar (ANOVA; $p=0.38$ ) among treatments. After the incubation period, for treatments with $\mathrm{Cu}$ concentration lower than $20 \mathrm{nM}$, the bacterial cell abundance slightly increased (ANOVA; $p<0.05)$ compared to $\mathrm{T} 0$, while it decreased for $\mathrm{Cu}$ concentrations of 30 and $60 \mathrm{nM}($ ANOVA; $p<0.01)$.

In both investigated sites, principal component analysis (PCA) on cell abundance of the different identified groups showed that picoplankton composition in mesocosms was more influenced by the incubation experiment period rather than $\mathrm{Cu}$ seawater content (Fig. S2).

\subsection{Biofilms visualization on MPs}

The visualization of microbial cells using CLSM (Fig. 2, Fig. S3) showed that microbial colonization settled on MPs in incubation experiments conducted at both Pt12 and Pt41p whereas MPs incubated with $0.2 \mu \mathrm{m}$ sterile filtered seawater (control treatments) did not show any microbial colonization. In addition, using specific markers, exopolysaccharide (EPS) were also detected within the biofilm formed on MPs, thus showing enriched regions in proteins (FITC) or sugar (concanavalin A and calcofluor white) (Fig. 2). 


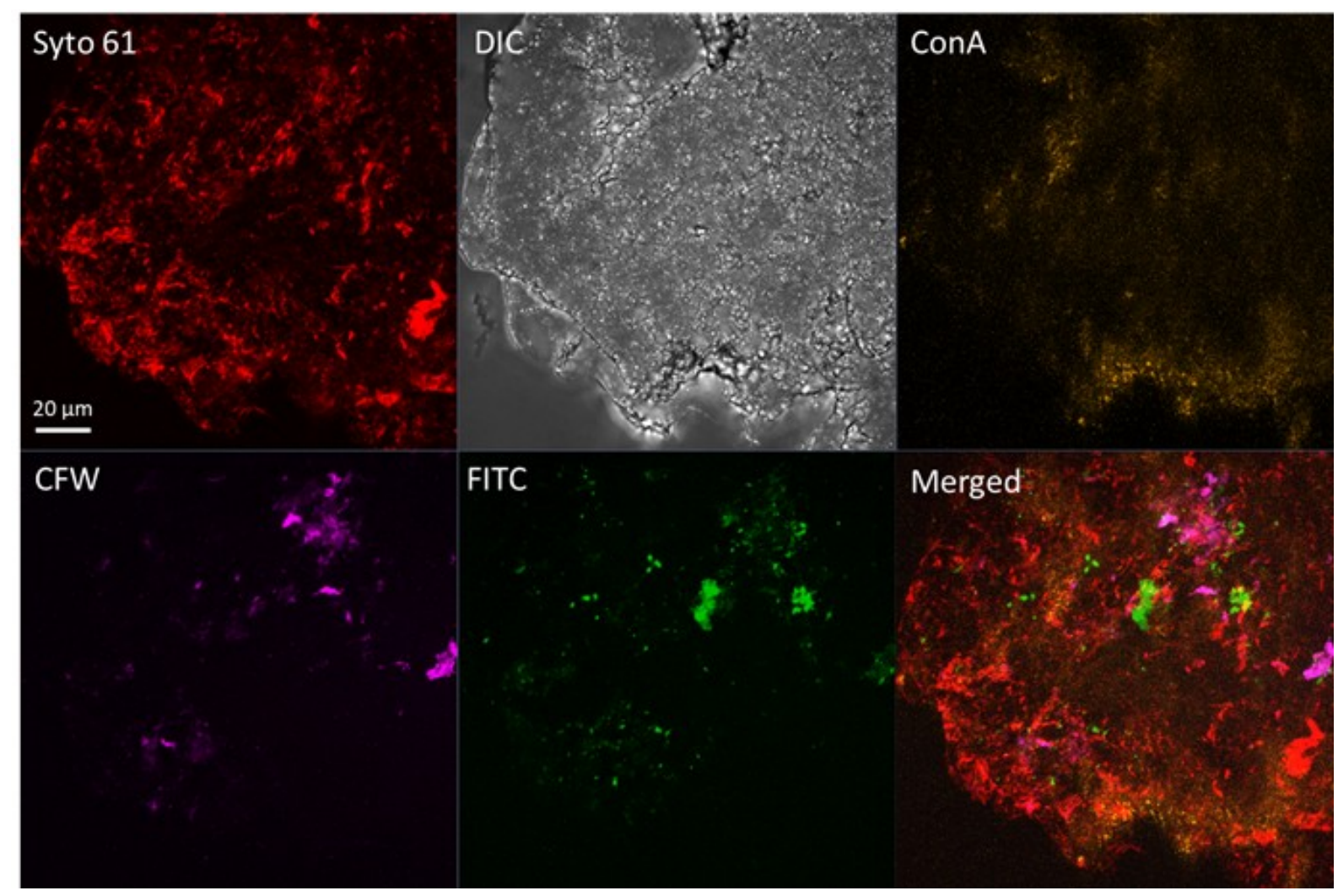

Figure 2: Confocal Laser Scanning Microscopy of microplastics. Attached microbial cells were visualized using the SYTO 61 as well as differentiated interference contrast microscopy (DIC). In addition, exopolymeric substances (EPS) characterizing biofilm development were visualized using FITC (proteins), concanavalin A (ConA, sugar) and calcofluor white (CFW, sugar).

\subsection{Effect of an increasing gradient of $\mathrm{Cu}$ on biofilm and its bioaccumulation on MPs}

In the water from Pt12 (small bay of Toulon), following an increasing gradient of $\mathrm{Cu}$ concentrations (between 30 and $400 \mathrm{nM}$, Fig. S4), the amount of bioaccumulated $\mathrm{Cu}$ per dry weight of MPs exhibited a significant increase ( $A N O V A ; F=23.3 ; d f=4 ; p<0.01$ ), with values ranging between $18 \pm 7$ and $119 \pm 30 \mathrm{nmol} / \mathrm{g}$ MPs (Fig. 3). Conversely, although not significantly different due to the variability within triplicates (ANOVA; 
$F=3.1, d f=4, p=0.07), \mathrm{Kd}$ seemed to exhibit a decrease of its average value, from $970 \pm 437$ to $380 \pm 83 \mathrm{~L} \mathrm{~kg}^{-1}$ for treatments with 30 and $400 \mathrm{nM}$ of $\mathrm{Cu}$, respectively. In the sterile filtered treatment, both bioaccumulated $\mathrm{Cu}$ $($ ANOVA; $F=31.9 ; d f=4 ; p<0.01)$ and $\mathrm{Kd}(A N O V A ; F=7.7 ; d f=4 ; p<0.01)$ were low (Fig. 3).

In the water from Pt41p (large bay of Toulon), the amount of bioaccumulated $\mathrm{Cu}$ per dry weight MPs was similar between treatments (ANOVA; $F=0.8 ; d f=4 ; p=0.53$ ), ranging between $0.52 \pm 0.06 \mathrm{nmol} / \mathrm{g} \mathrm{MPs}$

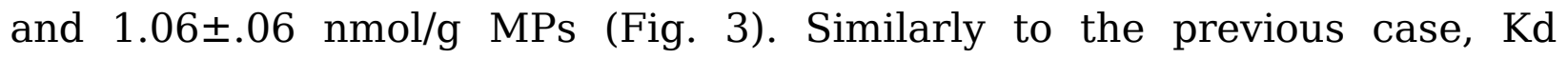
exhibited an decrease with the increasing gradient of $\mathrm{Cu}$ (ANOVA; F=5.9; $d f=4 ; p=0.02$ ), ranging between $12 \pm 10 \mathrm{Kg} \mathrm{L}^{-1}$ and $66 \pm 15 \mathrm{Kg} \mathrm{L}^{-1}$.

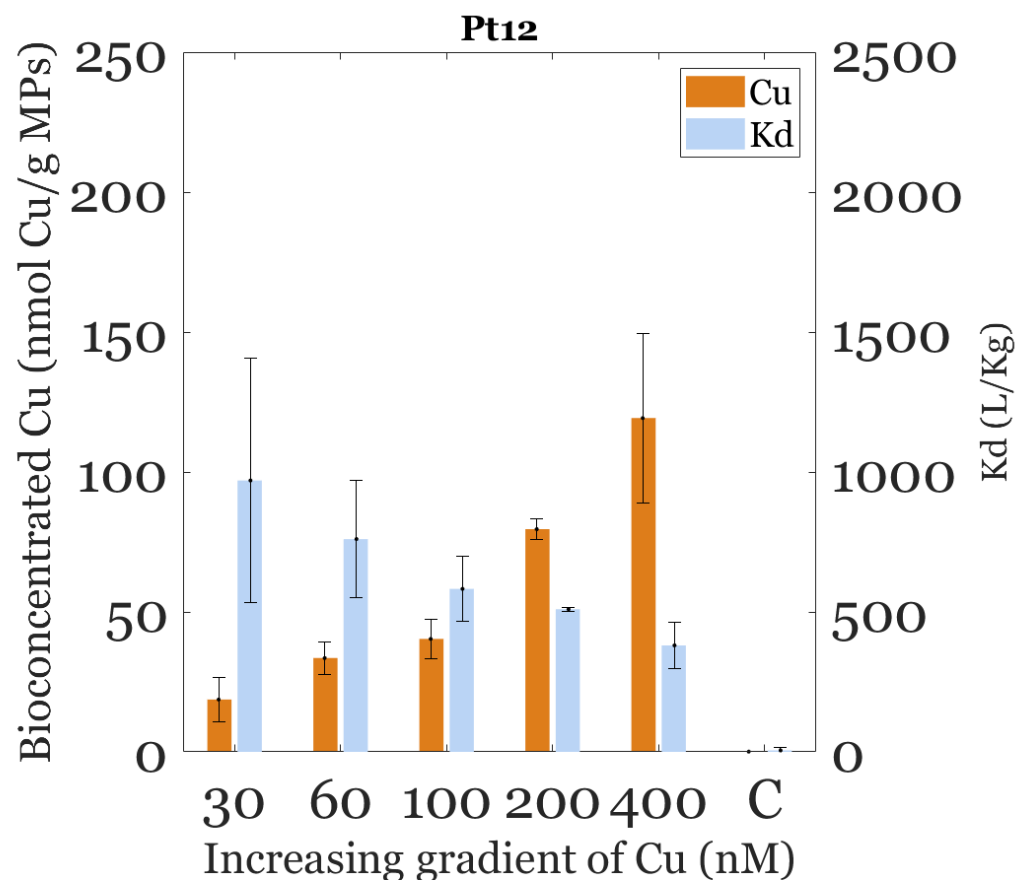




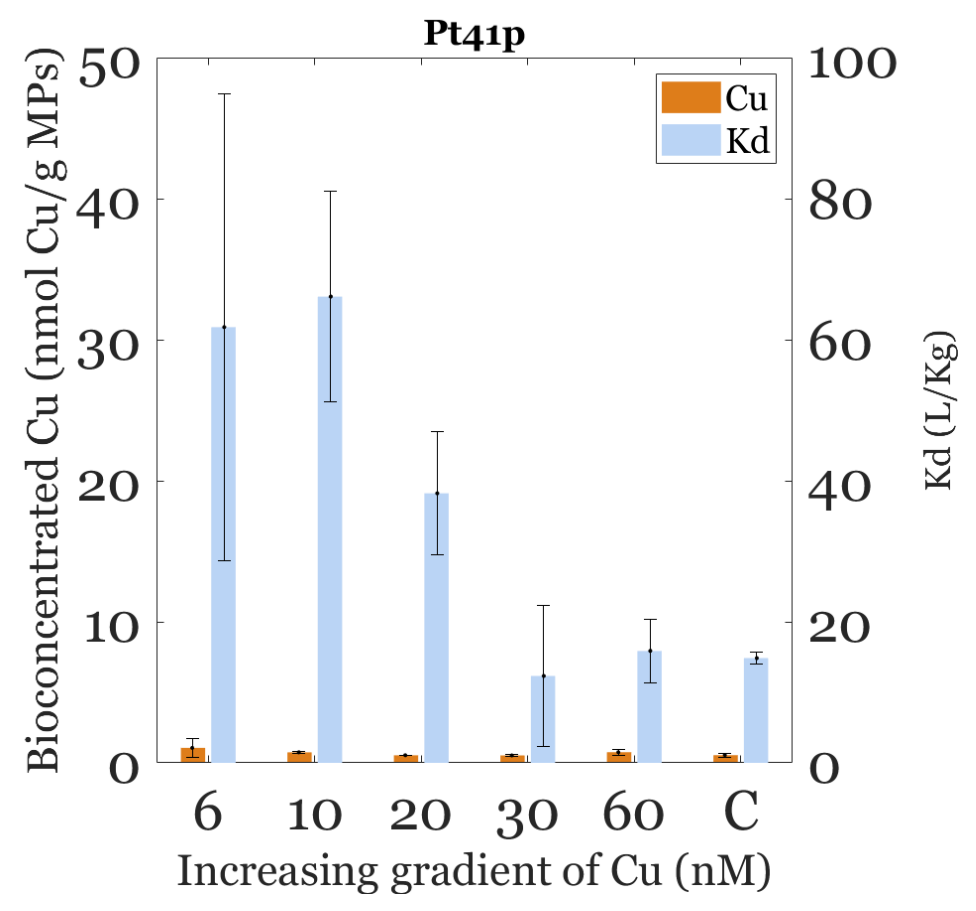

Figure 3. Bioaccumulated $\mathrm{Cu}$ on microplastics at the scale of the incubation period and its associated repartition coefficient $(\mathrm{Kd})$ at Pt12 (small bay) and at Pt41p (large bay). C refers to treatments with sterile filtered seawater. Note that the scale of y axes of both bioaccumulated $\mathrm{Cu}$ and Kd are different at Pt12 compared to Pt41p.

\subsection{Alpha diversity of microbial biofilm on MPs}

The Illumina Miseq run produced 1984472 and 2340978 paired-end reads, leading to 1543558 and 2018175 merged sequences for 16SrDNA and 18SrDNA gene sequencing respectively. 1030 and 512 OTUs could be generated after clustering for prokaryotes and eukaryotes respectively. Archaea were excluded from the prokaryotic set of reads $(<0.5 \%)$. Some samples could not be amplified due to low DNA extracts (Pt41p_C2r1 and r3, C3r1 and r2, C4r3 for 16S rDNA and Pt41p_C5r3 for 18S rDNA). Sequence normalization by a random resampling to the sample with the fewest sequences was performed $(n=13345$ and 24308 for prokaryotes and 
eukaryotes respectively), leading to the exclusion of few samples (Pt12_C5r3 for 16S rDNA and Pt41p_C1r2 and C3r2 for 18S rDNA).

All alpha diversity indexes (Fig. 4) displayed significant differences among biofilms developed on MPs, within seawater from the two sites (Pt12 and Pt41p) and for both prokaryotes and eukaryotes. Richness and diversity were always much higher at Pt12 (small bay) than at Pt41p (large bay). Considering the influence of $\mathrm{Cu}$ seawater content on prokaryotes, only the highest concentration (400 nM) decreased the Chao 1 at Pt12 and both Chao 1 and Shannon index at Pt41p, when compared to natural seawater. No significant difference could be noticed for eukaryotes regardless of the index. 

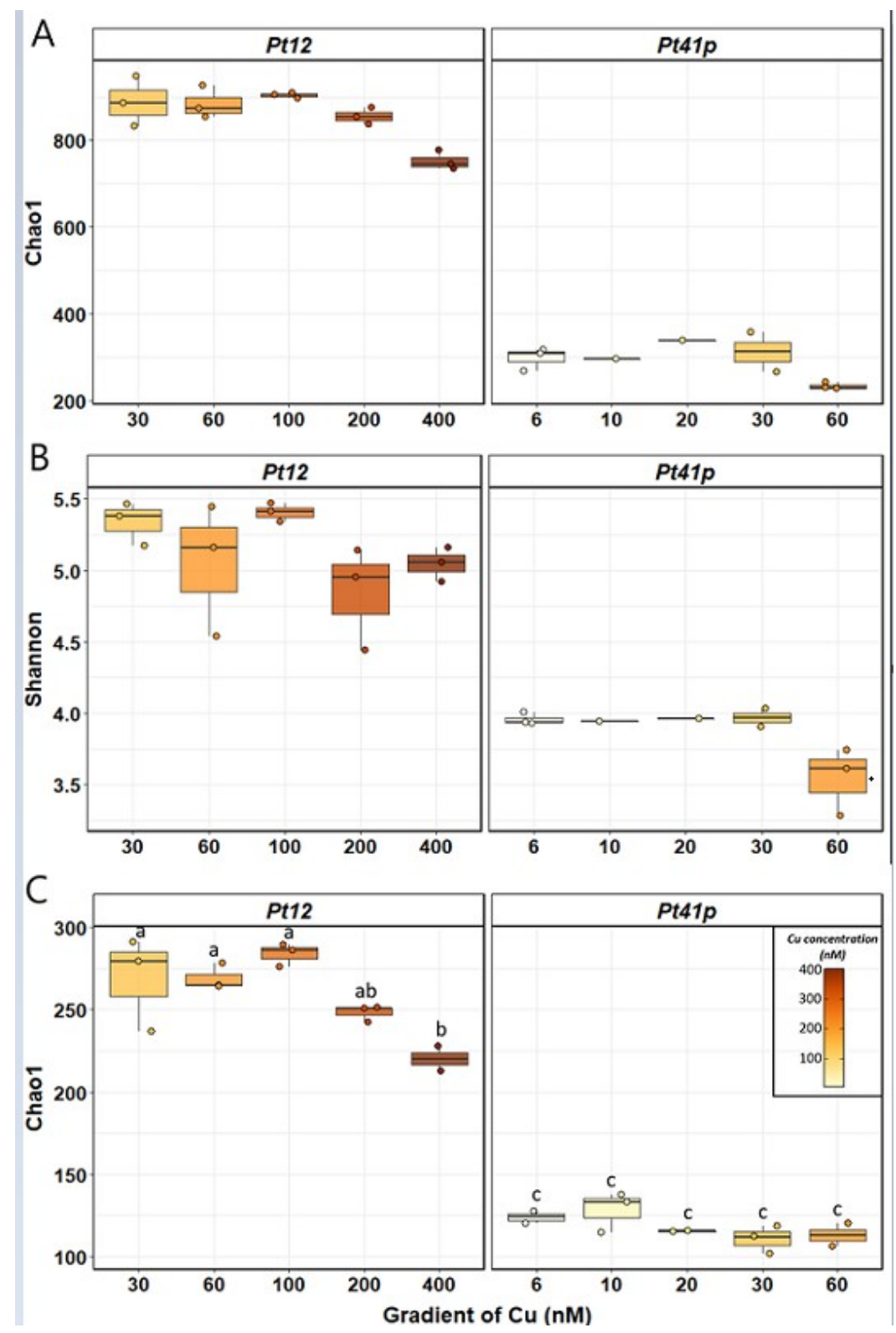

Figure 4: Alpha diversity indexes for experiments at both sites Pt12 and Pt41p: Chao1 index (A) and Shanon index (B) for prokaryotes and Chao1 index for eukaryotes (C).

\subsection{Beta-diversity and composition of microbial biofilms on MPs}

For both prokaryotic and eukaryotic communities, the first clustering factor was definitely the site (Fig. 5). In addition, in each incubation experiment, a clear shift of natural communities was observed on the y-axis following the 
increasing gradient of $\mathrm{Cu}$, except for eukaryotes from Pt41p for which no dissimilarity could be noticed (Fig.5; panel B).
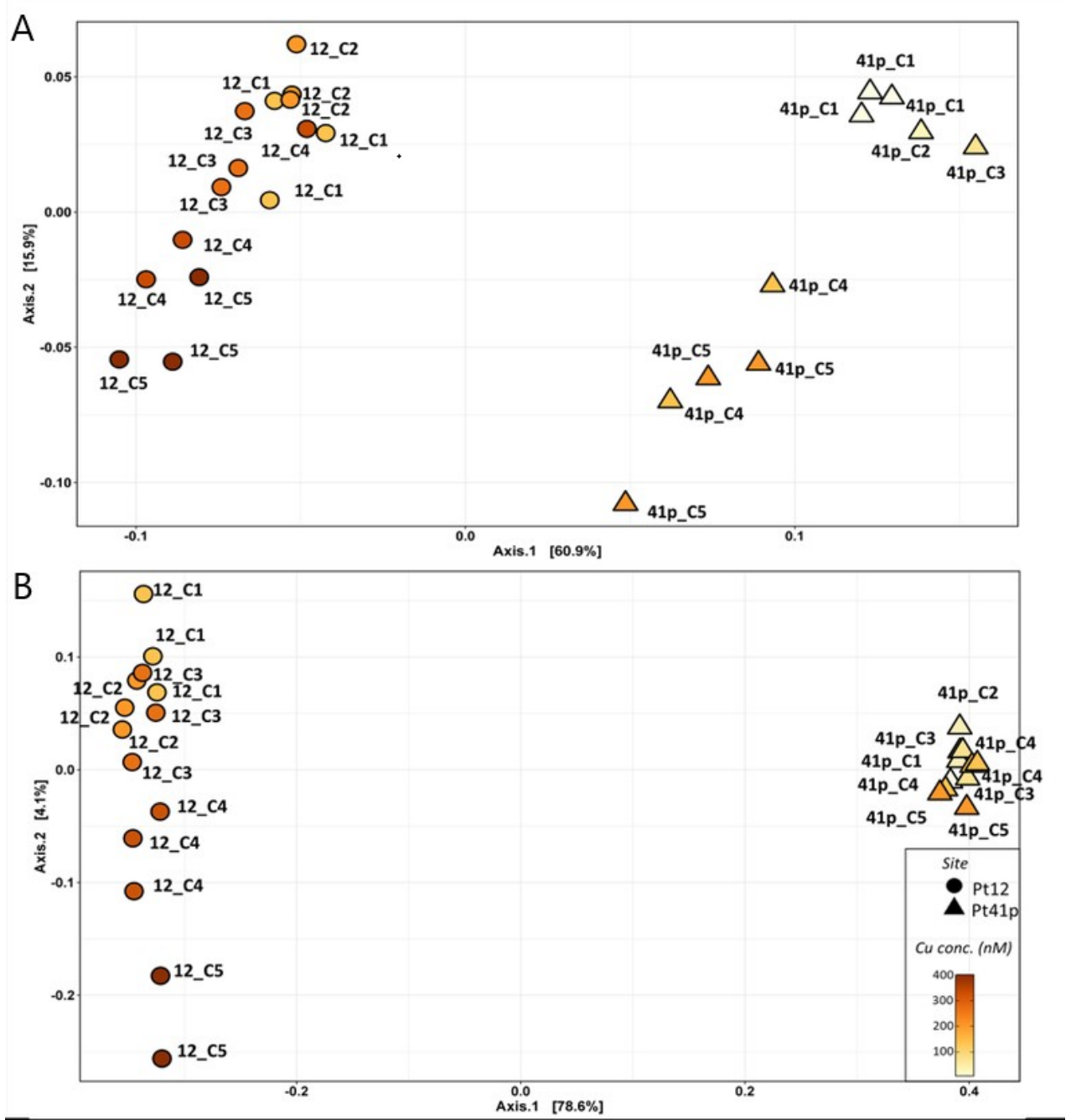

Figure 5: Principal Coordinates Analysis (PCoA) of biofilm prokaryotes (A) and eukaryotes (B) from microplastics, for incubation experiments conducted in the seawater from the Pt12 (circles) and Pt41p (triangles). Clustering was studied using Weighted Unifrac distances for prokaryotes and Unweighted Unifrac distances for eukaryotes.

Prokaryotic biofilm communities were dominated at the two sites by three classes: alpha-, gammaproteobacteria and Bacteroidia. The dissimilarity between communities from the two sites was shown at the family level with communities dominated by Cryomorphaceae (mainly 
Luteibaculum, 5 to 30\%) and Rhodobacteraceae (mainly Tateyamaria, 22 to $32 \%$ ) at Pt12, but Flavobacteriaceae (mainly Aureicoccus and Pseudofulvibacter, 28 to 43\%) and Sphingomonadaceae (mainly Erythrobacter, 7 to 14\%) at Pt41p (Fig. 6A and S5). SIMPER analyses showed that the prokaryotic taxa the most involved in the dissimilarity between mesocosms with natural seawater at Pt12 $(\mathrm{C} 1=30 \mathrm{nM})$ and with $200 \mathrm{nM}$ of $\mathrm{Cu}$ (C4) were two OTUs affiliated to Luteibaculum (Cryomorphaceae), an unknown Rhodobacteraceae and Croceibacterium (Flavobacteriaceae), with the three first being enriched in $\mathrm{Cu}$ (Table $\mathrm{S} 1$ ). Taxa the most involved in the dissimilarity between mesocosms filled with natural seawater at Pt41p (D1) and with $60 \mathrm{nM}$ of copper (D4) were four OTUs affiliated to Flavobacteriaceae. Aureicoccus and Winogradskyella showed higher relative abundance in D1 whereas Pseudofulvibacter and Croceibacter in D4 (Table S1). In addition, an unknown Rhodobacteraceae and two Sphongibacteraceae, Spongibacter and Erythrobacter, highly contributed to the dissimilarity between D1 and D4 and were more abundant in D4 too. 

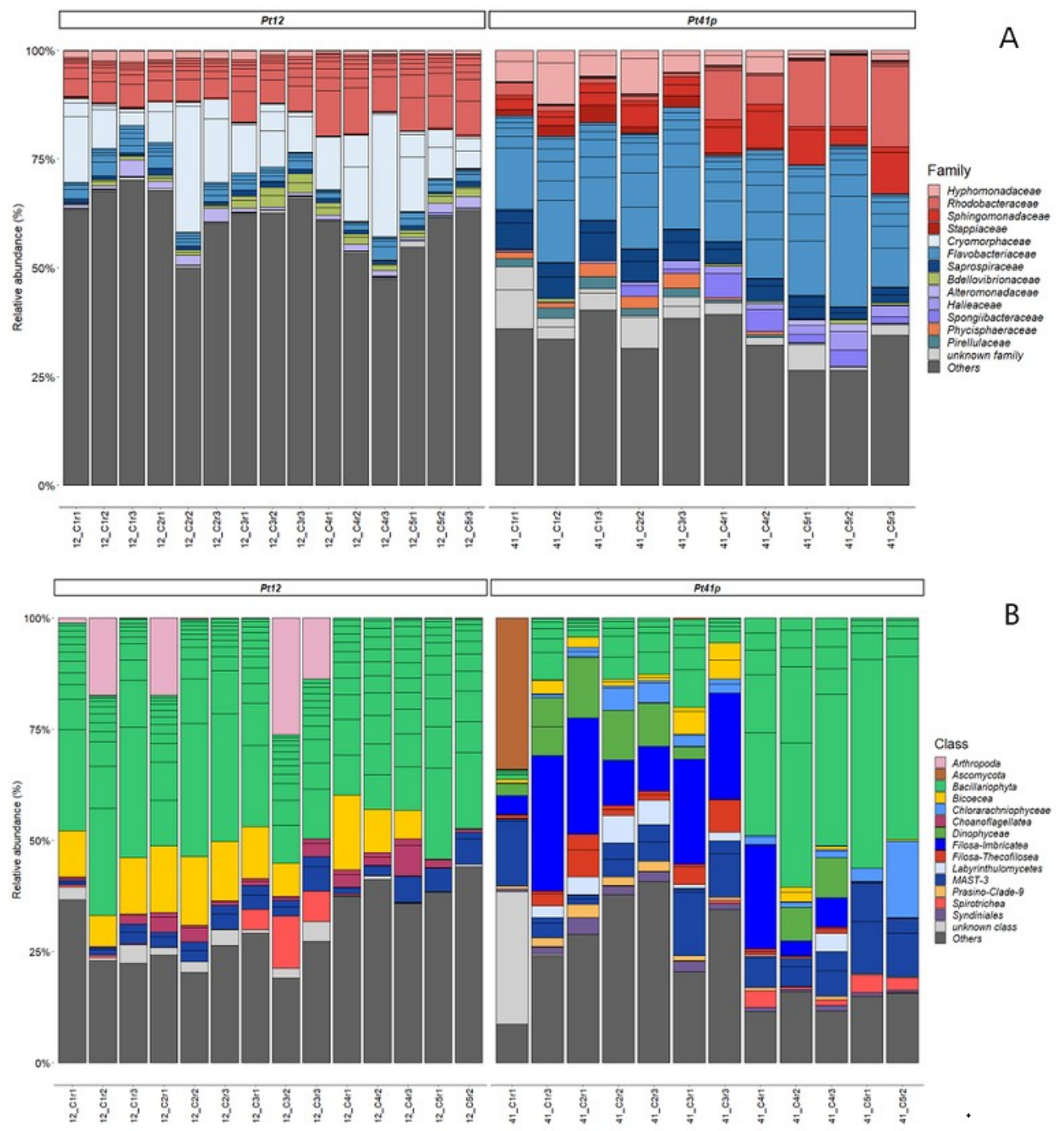

Figure 6: MPs biofilm community composition in the experiments with the seawater from the two sites (Pt12 and Pt41p) at the family level for prokaryotes (A) and the Class level for eukaryotes (B).

Biofilm eukaryotic communities were mostly composed of microeukaryotes (Fig. 6B and S6). Oithona, a planktonic copepod (crustaceans), ubiquitous and abundant in oceans, which was probably entrapped in biofilms when filtered, was the only multicellular organism identified, and only in Pt12 samples without copper concentration exceeding $100 \mathrm{nM}$. Microeukaryotes were dominated by diversified Bacillariophyta at Pt12 (41 to 78\%), whereas only samples with the two 
highest copper concentrations (30 and $60 \mathrm{nM}$ ) exhibited similar dominance at Pt41p. Raphid pennates strongly dominated at Pt12 irrespective of the copper concentration (25 to 57\%). Among them, Cylindrotheca closterium or Pseudo-Nitzschia appeared to be sensitive to copper whereas Nitzschia or Surirella were enriched in high copper concentration (from 4 to $23 \%$ and 1 to $6 \%$, respectively). Similarly, araphid pennates, without taxonomic affiliation at the genus level, were enriched with $\mathrm{Cu}$ addition, both at Pt12 (from 2 to 13\%) and Pt41p (6 to 16\%, even if the percentage decreased just for the highest copper concentration). Polar centric Mediophyceae exhibited the same trend at Pt41p (3 to $44 \%$ ).

Bicoecea (unicellular flagellates, Stramenopiles) accounted between 8 to $20 \%$ at Pt12 and from 2 to $8 \%$ at Pt41p, except at the highest $\mathrm{Cu}$ concentration for the two sites (less than 1\%). MAST-3J (Stramenopiles) represented from 1 to $9 \%$ at Pt12, with a decrease at the highest $\mathrm{Cu}$ concentration, whereas a higher percentage was observed at Pt41p (7-20\%) without any copper effect. Unidentified centroheliozoa completed the community at Pt12, with a clear decrease at the highest $\mathrm{Cu}$ concentration (from 8 to 1\%). Dinophyceae, including Pentapharsodinium that could be present as cysts in biofilms, represent generally around $2 \%$ but accounted for up to $13 \%$ of the reads at Pt41p with a decrease for the two highest $\mathrm{Cu}$ concentrations. Picoplanktonic phototrophs in the Prymnesiophyceae accounted for up to $6 \%$ at Pt41p, showing a sensitivity to the highest copper concentration too. Moreover, Filosa Imbricateae and Thecofilosea (Rhizaria) appeared to be also sensitive to copper, with percent decreasing from 30 and 16, respectively, to $0 \%$ at the highest copper concentration at Pt41p. Finally, Fungi accounted for less than 2\% (except one sample at Pt41p), without clear variation depending on the site or copper concentration, as well as Ciliophora (from 0 to $11 \%$ ).

SIMPER analyses showed that the eukaryotic taxa was the most involved in the dissimilarity between mesocosms with $\mathrm{C} 1$ and $\mathrm{C} 4$, where 
OTUs mostly affiliated to Bacillariophyta but with different taxa abundances in the two conditions (Table S1, 7). C4 was used rather than C5 because the latter appeared less representative of natural ecosystems. Two OTUs of Nitzschia, one Amphiprora and an additional but unaffiliated Raphidpennate contributed to the dissimilarity between conditions and were abundant in C4 whereas Pseudo-Nitzschia and an additional but unaffiliated Raphid pennate were more abundant in C1. The copepod Oithona, the flagellate Bicosoeca, the ciliate Holosticha and a Choanoflagellatea were the other contributors to the dissimilarity between $\mathrm{C} 1$ and $\mathrm{C} 4$. The most involved taxa in the dissimilarity between D1 and D4, and enriched in D4, were mostly OTUs affiliated to Bacillaryophyceae (Polar centric Mediophyceae, araphid and raphid pennates), whereas taxa abundant in D1 were heterotroph microeukaryotes (Filosa imbricatea, Sordaryomycetes, centroheliozoa or MAST-3J).

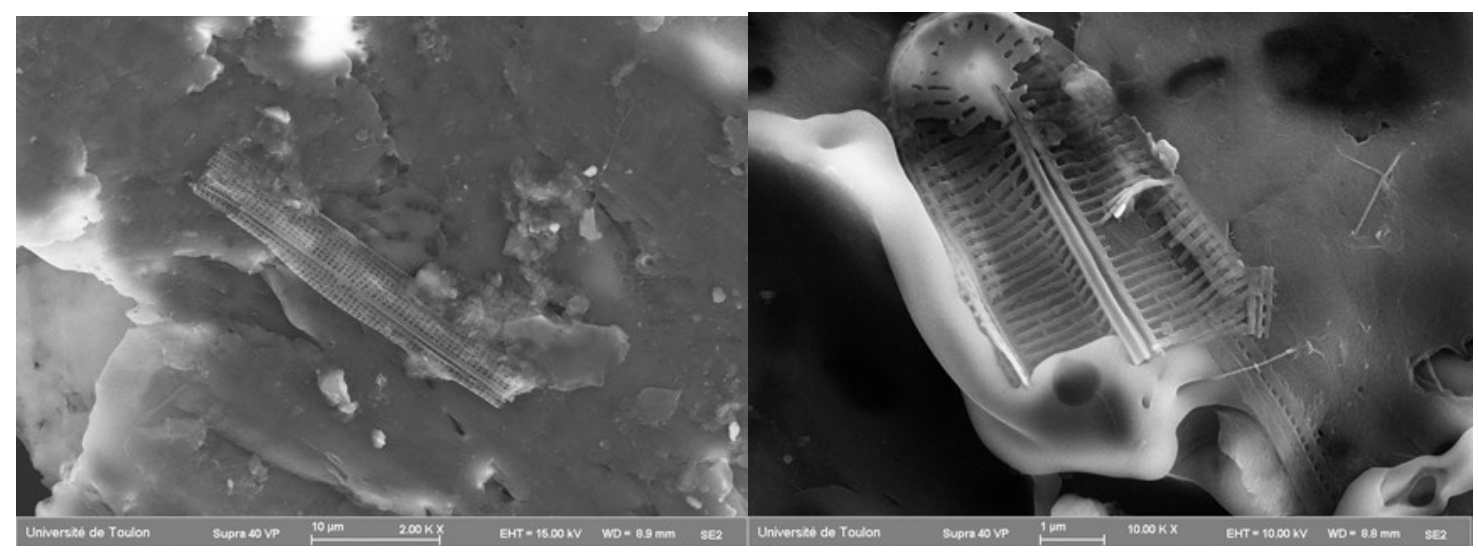

Figure 7: Visualization of diatoms within the biofilm developed onto MPs at Pt12 incubation experiment, using scanning electron microscopy.

Networks allowing to identify the co-occurrence among prokaryotic and eukaryotic taxa on MPs were constructed using CoNet for each of the two experiments (Fig. 8, Table S2). For Pt12, the main cluster of the network displayed 79 nodes (OTUs) associated with 95 degrees or edges. Ten small clusters with only two to three nodes completed the network. Most of the edges were positive (62\%). The ten nodes with the highest 
number of edges corresponded to five Rhodobacteraceae (Candidatus Rhodobacter lobularis, Pelagimonas, Roseobacter, Tateyamaria and an unknown genus) followed by five Bacillariophyta, four of them being araphid pennates including Grammatophora undulata. For Pt41p, the main cluster of the network displayed 45 nodes (OTUs) associated with 79 edges. Twelve small clusters with only two to four nodes completed the network. Most of the edges were positive (72\%). The ten nodes with the highest number of edges corresponded to three bacterial and seven eukaryotic OTUs showing the highest diversity. Bacteria belonged to the Flavobacteriaceae (Winogradskyella), Stappiaceae (unknown genus) and Pirellulaceae (Blastopirellula) when Eukaryotes were Bacillariophyta (Thalassiosira profunda and an unknown polar centric Mediophyceae) but also three Cercozoa (one unknown genus among Filosa Theocofilosa and another one among Filosa Imbricata, and a mixotrophic amoeboid-like microalgae Minorisa), a Prymnesiophyceae (Phaeocystis) and a Ciliophora (unknown genus among Strombidae). 


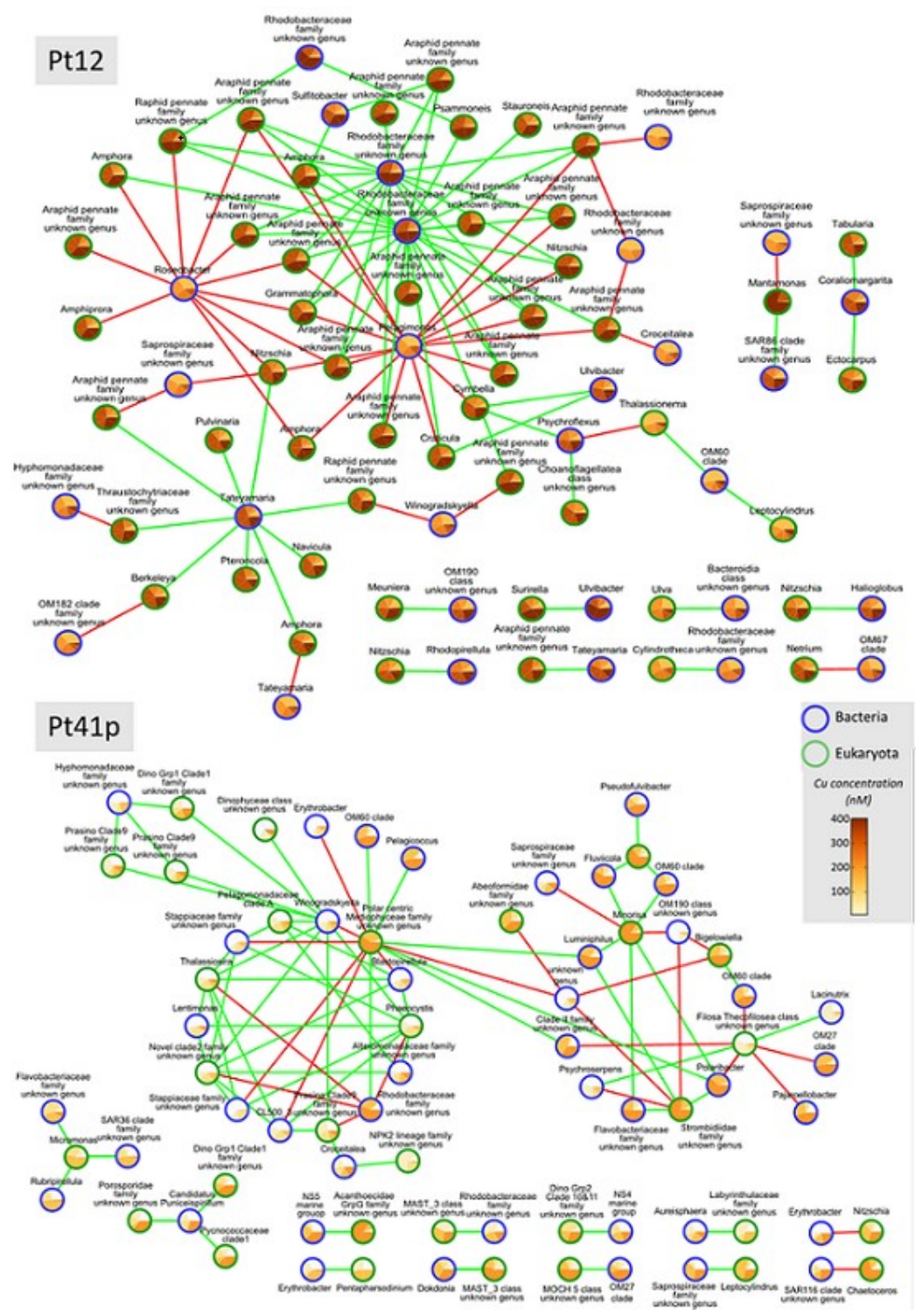

Figure 8: Interactions among prokaryotic and eukaryotic OTUs were identified using CoNeT (Co-occurrence Network) in the two experiments with seawater from the sites Pt12 and Pt41p. Blue circles stand for bacterial OTUs whereas green OTUs stand for eukaryotes. Relative abundances in each sample are indicated within circles. Samples are colored depending on the $\mathrm{Cu}$ content. Positive edges are in green whereas negative ones are in red. 


\section{Discussion}

In this study, for the sake of viability of encountered microbial communities, $\mathrm{Cu}$ was added in a range between 30 and $400 \mathrm{nM}$ and between 6 and $60 \mathrm{nM}$ when seawater was sampled from Pt12 (small bay of Toulon) and from Pt41p (large bay of Toulon), respectively, as $\mathrm{Cu}$ concentrations were shown to exhibit a decreasing gradient from the most enclosed part of the bay to the open waters (Coclet et al., 2018, 2021; Layglon et al., 2020). In agreement with in-situ observations (Coclet et al., 2018, 2019; Delpy et al., 2018), distinct picophytoplankton composition was observed in each incubation experiment, thus exhibiting picoeukaryotes as a dominant phytoplankton group in seawater form Pt12 (small bay of Toulon) and cyanobacteria (Synechococcus and Prochlorococcus groups) in seawater from Pt41p (large bay of Toulon). At the time scale of the incubation experiment, all phytoplankton groups as well as heterotrophic bacteria decreased overall following the increasing gradient of $\mathrm{Cu}$, thus supporting the role of $\mathrm{Cu}$ in shaping planktonic microbial community composition. Considering this context, this study aimed to demonstrate, using controlled conditions with natural seawater, that: (1) $\mathrm{Cu}$ concentrations in seawater controlled its bioaccumulation onto MPs, with this bioaccumulation strictly linked to biofilm formation and (2) $\mathrm{Cu}$ bioaccumulation shaped the microbial community within the biofilm formed on MPs.

\subsection{Copper bioaccumulation on MPs is due to biofilm}

In this work, abiotic alterations of MPs in link with light exposure and mixing (see method section) may have promoted adsorption of $\mathrm{Cu}$ onto their surface at the time scale of the incubation period. Yet, the low observed values in $0.2 \mu \mathrm{m}$ sterile filtered seawater treatments in both incubation experiments highly suggested the role of biofilm as a striking link within MPs-Cu interplay. Trace metals (TMs) bioaccumulation onto MPs through 
biofilm formation is still poorly resolved, especially in seawater. As a matter of fact, so far, most studies which reported MPs-TMs interaction in marine and/or freshwater systems focused on pristine microplastics, devoid of any biological colonization, but also on the influence of aging, resulting from physical alterations and/or photooxidation, on these pellets in promoting TMs adsorption (Turner and Holmes 2015; Brennecke et al., 2016; Mao et al., 2020). Nevertheless, there is increasing evidence that investigating the interaction between TMs and pristine MPs can be in fact misleading. Recently, reported studies have shown that biofilm developments on these synthetic particles eased metals accumulation, including $\mathrm{Cu}$ (Richard et al., 2019; Guan et al., 2020, Wang et al., 2020).

In this study, biofilm formation around MPs was proven in both studied sites. In addition, dissimilar alpha and beta diversity was observed in biofilms depending on the sites, but also $\mathrm{Cu}$ seawater content. This differences in biofilm formations between sites were reflected in $\mathrm{Cu}$ bioaccumulation, thus exhibiting quantitatively higher values in seawater from Pt12 (up to $119 \pm 30 \mathrm{nmol} / \mathrm{g}$ MPs) than Pt41p (up to $47 \pm 32 \mathrm{nmol} / \mathrm{g} \mathrm{MP}$ ), with a clearer increasing bioaccumulation of $\mathrm{Cu}$ following seawater $\mathrm{Cu}$ contents in Pt12. Higher alpha-diversity combined to higher DNA extracts (data not shown) suggested that greater biofilm biomass occurred on MPs at Pt12, in agreement with higher $\mathrm{Cu}$ bioaccumulation. Biofilm accumulation of metals have been essentially highlighted in freshwater systems (Ancion et al., 2010; Tien and Chen, 2013), with retention time up to 14 days before a subsequent release into the surrounding waters (Ancion et al., 2010). Within the biofilm, the sorptive properties of EPS have been shown to effectively bind large amounts of metals (Decho, 2000 and references therein). In this study, EPS among others, may have promoted $\mathrm{Cu}$ bioaccumulation. In fact, in the water, $\mathrm{Cu}$ speciation is dominated by organic complexes (Wong et al., 2018 and reference herein), especially in areas where dissolved organic matter (DOM) is found at high 
concentrations. TMs cations complexation by organic ligand or organic matter occurred through several complexation acidic sites (Luo et al., 2009), defined by their concentration and complexing constant. Such parameters are closely related to the surrounding DOM. For example, the complexing affinities towards $\mathrm{Cu}$ of a natural DOM considered, from a river end-member to seawater end-member, was revealed to change according to the location along an estuary: from a concentrated one-type of complexing site with a modelled concentration and a high constant to a 2-types of complexing sites with lower concentrations but higher constants (Louis et al., 2009). Similarly, organic ligands produced in the biofilm matrix, EPS for example, will differ from one incubation experiment to another, as richness and diversity indices differ among biofilms. The concentrations and complexing constants of each produced biofilm could not be determined, the dedicated experiments needing an important quantity of organic material (Louis et al., 2009), which is impossible when dealing with the very thin biofilm layer around MPs. Yet, it is well known that a biofilm will produce organic ligands whose nature and quantity depends on the biofilm composition (Fang et al., 2014; Mahapatra et al., 2020). It was already demonstrated that the biofilm cultivated on polyethylene molecularly differs from a biofilm developing on cobblestones, with a weaker interaction between EPS and $\mathrm{Cu}$ in the polyethylene biofilm (Wang et al, 2020). It is therefore obvious that the biofilm developing in each of the tested conditions (and especially seawater) of this study will have its own composition and hence organic ligands properties. This is reflected in copper accumulation.

\subsection{Biofilm community structure is primarily controlled by the sampling site}

Sampling site clearly appeared as the primary driver for biofilm community shaping. Even though $\mathrm{Cu}$ seawater contents were significantly different at the two sites, $\mathrm{Cu}$ alone may not explain differences in biofilm 
microbial community. In fact, a recently conducted study at these two sites, as well as at three additional ones in the Toulon bay, has concluded that the $\mathrm{Cu}$ gradient failed to explain the clustering of prokaryotic community structure of mature biofilms (Coclet et al., 2021). In this same study, interestingly, most of the reported environmental biofilm community drivers, such as temperature, $\mathrm{pH}$, dissolved oxygen, and nutrients, were measured and did not show any significant difference among sites, suggesting that additional parameters like DOM, hydrodynamics or topdown control, among others, could have played a role in shaping biofilm microbial community (Catao et al., 2019; Mazoyer et al., 2020; Ferguson et al., 2021). In other studies, performed on biofilms formed on large artificial polymer surfaces, environmental parameters also clearly drive biofilm communities which was reported in the litterature too (e.g. Oberbeckman et al., 2016; 2018; Lawes et al., 2016; Briand et al., 2017; Catao et al., 2021). When samples within the plastisphere failed to be related to environmental factors characterizing the sampling site (e.g. Bryant et al., 2016, Dussud et al., 2018), the buoyant character of plastic promoting the influence of multiple environmental conditions may provide an explanation.

In addition, while supplying seawater from Pt41p and Pt12 with the same concentration of $\mathrm{Cu}(60 \mathrm{nM})$, biofilm communities on MPs did not converge neither for prokaryotes nor eukaryotes, thus confirming that $\mathrm{Cu}$ did not primarily drive biofilm microbial communities. However, the wellknown toxicity influence of $\mathrm{Cu}$ on phytoplankton can indirectly influence biofilm, through an exerted control on cell abundance in one hand but also via alteration of DOM nature in the other hand. Finally, we assume that the two clusters of biofilm communities observed in mesocosms of the two sites were also the result of different initial planktonic communities. As a matter of fact, biofilm taxa come from the rare planktonic community, particularly copiotrophs, which make their determination within the bacterioplankton 
difficult, using classical Illumina approach (Zhang et al., 2019, Catao et al., 2021, Coclet et al., 2021).

Communities on MPs included typical biofilm taxa. Discrepancies for taxa affiliation between this study and the previous biofilm study on polymer surface in the bay of Toulon (Briand et al., 2017) should probably be associated with the considered surface size of plastic (large polymers versus MPs), the type of conducted experiments (mesocosm versus field study), the immersion time (13 versus 30 days) but perhaps the interannual variability too. Cryomorphaceae taxa enriched in Pt12 biofilms seem more predominant in coastal ecosystems, with enhanced organic loads (Bowman, 2020), and also enriched in the marine plastisphere (Oberbeckmann et al., 2016). The co-occurrence network analysis highlighted the central role of several Rhodobacteraceae in interactions with eukaryotes. In addition to the low richness and diversity observed in biofilms from Pt41p, taxa reputed as pioneer ones, like Alteromonas (Dang and Lovell, 2000; Lee et al., 2008; Pinto et al., 2019) or Hyphomonadaceae (Dang and Lovell, 2016), could be identified, which strengthen our hypothesis of weak biofilms on MPs with seawater from Pt41p.

Considering the poorly studied eukaryotes on MPs (Kettner et al.2019), most of them were microeukaryotes, as multicellular one's development should be limited by the size of MPs and the incubation time. Unfortunately, the taxonomic affiliation of the 18SrDNA gene (Whatever the data bank PR2 or Silva, data not shown) allowed the identification of only a few of OTUs to the genus level in biofilms on MPs (41\% for PR2). Diatoms (Bacillariophyta), especially pennates, clearly dominated the most anthropized site (Pt12) showing a high diversity of genera among the raphid pennate (Amphiprora, Cylindrotheca, Navicula, Nitzchia, Pseudo-Nitzschia, Surirella). Likewise, the co-occurrence network underlined the significance of diatoms in interactions with prokaryotes and primarily with Rhodobacteraceae. Despite often identified on scanning electron microscopy (e.g. Zettler et al. 2013, 
Kirstein et al., 2018), diatom communities were scarcely studied on MPs compared to prokaryotes. Diatoms in biofilms were studied on large artificial surfaces, all using microscopic approaches, mainly in tropical areas, and with the aim to describe their diversity depending on the substrate type including antifouling coatings (Patil and Anil, 2005, Mitbavkar and Anil, 2008, Molino and Wetherbee, 2008, Zargiel et al., 2014,

Briand et al., 2017, Muthukrishnan et al., 2017). This major microphytobenthic taxa was conversely highly investigated in freshwater ecosystems, mostly in the context of bioindication (e.g. Sabater et al., 2017, Rivera et al., 2018, Polst et al., 2018).

Pt41p exhibited the highest number of families with a lower importance of diatoms in the natural seawater condition. The presence of vagile predators of bacteria like unicellular flagellates Bicoecea or amoeboids-like Filosa Imbricateae and Thecofilosea could be explained. However, diatoms are mainly represented by polar centric mediophyceae including Chaetoceros, Dinophyceae including Pentapharsodinium or picoplanktonic phototrophs in the Prymnesiophyceae, which are more surprising to be found in biofilms. Specifically considering the centric diatoms, some authors tend to consider them as members of the plastisphere, but considering their preferential planktonic lifestyle and taken in consideration that specific lifestyle occurred for other microorganisms as bacteria (e.g. Wright et al., 2020), we may hypothesized that such polar centric diatoms may belong to the rare biofilm community. Consequently, a contamination issue with planktonic taxa from the mesocosms seawater during the filtration of the MPs should not be excluded. Moreover, the high number of polar centric mediophyceae, which increased with $\mathrm{Cu}$ addition in biofilms on MPs especially in Pt41p, could be also linked to the relative increase of nanophytoplankton observed in the mesocosm seawater (Figure S1-2).

\subsection{Cu also controlled biofilm community on MPs}


As mentioned above, $\mathrm{Cu}$ was not identified as the main driver of biofilm community on plastic surface in a previous experiment with natural seawater $\mathrm{Cu}$ concentrations in Toulon bay (Coclet et al., 2021). Alphadiversity appeared not affected in this study as well except at the highest $\mathrm{Cu}$ concentration (400 nM), which though is not environmentally realistic as such high concentrations are not naturally observed. Conversely, Cu clearly influenced the beta-diversity of biofilm communities for each site, except for eukaryotes with seawater from Pt41p. It may look contradictory because substrates were immersed in waters from the same sites, and conventional plastics (polycarbonate and polyethylene in these two cases) are now reputed to exhibit similar biofilm communities (Kirstein et al., 2018, Wright et al., 2020). However, the size of the substrates was significantly different with $5 \times 5 \mathrm{~cm}$ coupons in the previous experiment (Briand et al., 2017) whereas MPs were used here. Hence, thicker biofilms have probably grown on MPs (Fazey and Ryan, 2016), allowing higher interactions between copper and biofilm cells, consequently with a higher selection within the biofilm communities compared to thick and mature biofilms observed on large substrates. The substrate size effect was still not fully studied but CLSM pictures confirmed the presence of thin biofilms on MPs.

Biofilms on MPs formed with the seawater from Pt12 exhibited higher richness, diversity and $\mathrm{Cu}$ bioaccumulation than at $\mathrm{Pt} 41 \mathrm{p}$, which suggested that a higher biomass, including EPS. While some EPS were clearly visualized with CLSM, their more in-depth study and characterization may provide a better understanding of interactions with metals. As two dissimilar biofilm communities occurred with seawater from the two sites, the assumption of dissimilar produced EPS can be made. However, the higher resulting $\mathrm{Cu}$ bioaccumulation in Pt12 compared to Pt41p could also relate to a quantitatively higher EPS production rather than the production of qualitatively different EPS. Even reputedly complex to study, EPS would be a key component for further insight regarding the interaction between 
biofilm and metal bioaccumulation (Flemming et al., 2016). The relative contribution of bacteria and diatoms to this production will be another important key point to address as well.

The Rhodobacteraceae genus Tateyamaria which was observed as one of the most enriched taxa at Pt12 following $\mathrm{Cu}$ content increase here, was already enriched in the most contaminated site in the previous study in the Toulon bay (Coclet et al., 2021). In addition, the network analysis highlighted the co-occurrence of this genus with several diatoms (Amphora, Berkeleya, Navicula, Nitzchia, Pteroncola), especially in high $\mathrm{Cu}$ concentration. Nevertheless, it remains difficult to conclude on simple coselection, direct or indirect interactions. Tateyamaria was also reported as a biomarker on copper-based antifouling paints, with a specific correlation with the abundance of the copper resistance gene CueO (Catao et al., 2021). Similarly, the relative abundance of Erythrobacter (Sphingomonadaceae) increased in biofilms from Pt41p with the increasing copper content, which is consistent with its enrichment in biofilm community on copper-based antifouling coatings (Catao et al., 2019, 2021). As already reported for copper resistance in the context of antifouling paints, the selection was mainly observed at the genus or species level rather than family. As a matter of fact, especially considering two of the main families, Rhodobacteraceae and Flavobacteriaceae, it was already reported that both sensitive and tolerant to copper taxa were identified in the same biofilm communities (Catao et al., 2019, 2021).

Among Bacillariophyta, Cylindrotheca closterium or Pseudo-Nitzschia appeared to be sensitive to $\mathrm{Cu}$ whereas Nitzschia or Surirella, but also Amphora or Grammatophora to a lesser extent, were enriched in high $\mathrm{Cu}$ concentrations. Similarly, araphid pennates, without taxonomic affiliation at the genus level, were enriched with $\mathrm{Cu}$ addition, both at Pt12 and Pt41p. The selection of resistant taxa together with the decrease of sensitive ones indicated that, similarly as for freshwaters, community structure and/or 
specific taxa could be used for bioindication (Tlili et al., 2016, Vasselon et al., 2017). Indeed, Bacillaryophyta could be used to find out if MPs move through contaminated or non-contaminated sea waters, which could give information on MPs -followed current.

\section{Conclusion}

This study revealed a tight interaction among MPs, biofilm and $\mathrm{Cu}$ concentration in seawater of the bay of Toulon (NW Mediterranean Sea). Indeed, $\mathrm{Cu}$ bioaccumulation on MPs was clearly linked to biofilm. Furthermore, the seawater $\mathrm{Cu}$-content controlled biofilm bioaccumulation on MPs but was also involved in biofilm microbial communities shaping.

\section{Acknowledgement}

This study was conducted as part of the Interreg Marittimo SPLASH! (Stop alle plastiche in $\mathrm{H} 2 \mathrm{O}$ !) research project. The authors would like to thank the Regional Flow Cytometry Platform for Microbiology (PRECYM).

\section{References}

Acosta-Coley I, Mendez-Cuadro D, Rodriguez-Cavallo E, de la Rosa J, Olivero-Verbel J. Trace elements in microplastics in Cartagena: a hotspot for plastic pollution at the Caribbean. Marine pollution bulletin 2019; 139: 402-411.

Amaral-Zettler LA, Zettler ER, Mincer TJ. Ecology of the plastisphere. Nature Reviews Microbiology 2020; 18: 139-151.

Ancion P-Y, Lear G, Lewis GD. Three common metal contaminants of urban runoff $(\mathrm{Zn}, \mathrm{Cu} \& \mathrm{~Pb})$ accumulate in freshwater biofilm and modify embedded bacterial communities. Environmental Pollution 2010; 158: 2738-2745.

Andrady AL. Microplastics in the marine environment. Marine pollution bulletin 2011; 62: 1596-1605.

Antunes J, Frias J, Micaelo A, Sobral P. Resin pellets from beaches of the Portuguese coast and adsorbed persistent organic pollutants. Estuarine, Coastal and Shelf Science 2013; 130: 62-69.

Aretoulaki E, Ponis S, Plakas G, Agalianos K. A systematic meta-review analysis of review papers in the marine plastic pollution literature. Marine Pollution Bulletin 2020; 161: 111690.

Brennecke D, Duarte B, Paiva F, Caçador I, Canning-Clode J. Microplastics as vector for heavy metal contamination from the marine environment. Estuarine, Coastal and Shelf Science 2016; 178: 189-195.

Briand J-F, Barani A, Garnier C, Réhel K, Urvois F, LePoupon C, et al. Spatiotemporal variations of marine biofilm communities colonizing artificial substrata 
including antifouling coatings in contrasted French coastal environments. Microbial ecology 2017; 74: 585-598.

Bryant JA, Clemente TM, Viviani DA, Fong AA, Thomas KA, Kemp P, et al. Diversity and activity of communities inhabiting plastic debris in the North Pacific Gyre. MSystems 2016; 1: e00024-16.

Catão EC, Pollet T, Garnier C, Barry Martinet R, Rehel K, Linossier I, et al. Temperate and tropical coastal waters share relatively similar microbial biofilm communities while free living or particle attached communities are distinct. Molecular Ecology 2021a.

Catão EC, Pollet T, Misson B, Garnier C, Ghiglione J-F, Barry-Martinet R, et al. Shear stress as a major driver of marine biofilm communities in the NW Mediterranean Sea. Frontiers in microbiology 2019; 10: 1768.

Catão, Elisa CP, Gallois N, Fay F, Misson B, Briand J-F. Metal resistance genes enrichment in marine biofilm communities selected by biocide-containing surfaces in temperate and tropical coastal environments. Environmental Pollution 2021; 268: 115835b.

Coclet C, Garnier C, D’Onofrio S, Durrieu G, Pasero E, Le Poupon C, et al. Trace metal contamination impacts predicted functions more than structure of marine prokaryotic biofilm communities in an anthropized coastal area. Frontiers in microbiology 2021; 12: 292.

Coclet C, Garnier C, Delpy F, Jamet D, Durrieu G, Le Poupon C, et al. Trace metal contamination as a toxic and structuring factor impacting ultraphytoplankton communities in a multicontaminated Mediterranean coastal area. Progress in oceanography 2018; 163: 196-213.

Coclet C, Garnier C, Durrieu G, D'onofrio S, Layglon N, Briand J-F, et al. Impacts of copper and lead exposure on prokaryotic communities from contaminated contrasted coastal seawaters: the influence of previous metal exposure. FEMS microbiology ecology 2020; 96: fiaa048.

Coclet C, Garnier C, Durrieu G, Omanović D, D’Onofrio S, Le Poupon C, et al. Changes in bacterioplankton communities resulting from direct and indirect interactions with trace metal gradients in an urbanized marine coastal area. Frontiers in microbiology 2019; 10: 257.

Dang $\mathrm{H}$, Lovell CR. Bacterial primary colonization and early succession on surfaces in marine waters as determined by amplified rRNA gene restriction analysis and sequence analysis of 16S rRNA genes. Applied and environmental microbiology 2000; 66: 467.

Dang $\mathrm{H}$, Lovell CR. Microbial surface colonization and biofilm development in marine environments. Microbiology and molecular biology reviews 2016; 80: 91138.

Debroas D, Domaizon I, Humbert J-F, Jardillier L, Lepère C, Oudart A, et al. Overview of freshwater microbial eukaryotes diversity: a first analysis of publicly available metabarcoding data. FEMS Microbiology Ecology 2017; 93: fix023.

Decho AW. Microbial biofilms in intertidal systems: an overview. Continental shelf research 2000; 20: 1257-1273.

Delpy F, Serranito B, Jamet J-L, Grégori G, Le Poupon C, Jamet D. Pico-and nanophytoplankton dynamics in two coupled but contrasting coastal bays in the NW Mediterranean Sea (France). Estuaries and Coasts 2018; 41: 2039-2055.

Derraik JG. The pollution of the marine environment by plastic debris: a review. Marine pollution bulletin 2002; 44: 842-852. 
Dussud C, Meistertzheim A, Conan P, Pujo-Pay M, George M, Fabre P, et al. Evidence of niche partitioning among bacteria living on plastics, organic particles and surrounding seawaters. Environmental Pollution 2018; 236: 807-816.

Edgar RC, Haas BJ, Clemente JC, Quince C, Knight R. UCHIME improves sensitivity and speed of chimera detection. Bioinformatics 2011; 27: 2194-2200.

Escudié F, Auer L, Bernard M, Mariadassou M, Cauquil L, Vidal K, et al. FROGS: find, rapidly, OTUs with galaxy solution. Bioinformatics 2018; 34: 1287 1294.

Fang L, Yang S, Huang Q, Xue A, Cai P. Biosorption mechanisms of Cu (II) by extracellular polymeric substances from Bacillus subtilis. Chemical Geology 2014; 386: 143-151.

Faust K, Sathirapongsasuti JF, Izard J, Segata N, Gevers D, Raes J, et al. Microbial co-occurrence relationships in the human microbiome. PLoS comput biol 2012; 8: e1002606.

Fazey FM, Ryan PG. Biofouling on buoyant marine plastics: An experimental study into the effect of size on surface longevity. Environmental pollution 2016; 210: 354-360.

Ferguson RM, O'Gorman EJ, McElroy DJ, McKew BA, Coleman RA, Emmerson MC, et al. The ecological impacts of multiple environmental stressors on coastal biofilm bacteria. Global Change Biology 2021.

Flemming H-C, Wingender J, Szewzyk U, Steinberg P, Rice SA, Kjelleberg S. Biofilms: an emergent form of bacterial life. Nature Reviews Microbiology 2016; 14: 563.

Fossi MC, Panti C, Guerranti C, Coppola D, Giannetti M, Marsili L, et al. Are baleen whales exposed to the threat of microplastics? A case study of the Mediterranean fin whale (Balaenoptera physalus). Marine Pollution Bulletin 2012; 64: 2374-2379.

Guan J, Qi K, Wang J, Wang W, Wang Z, Lu N, et al. Microplastics as an emerging anthropogenic vector of trace metals in freshwater: Significance of biofilms and comparison with natural substrates. Water Research 2020; 184: 116205.

Guillou L, Bachar D, Audic S, Bass D, Berney C, Bittner L, et al. The Protist Ribosomal Reference database (PR2): a catalog of unicellular eukaryote small subunit rRNA sequences with curated taxonomy. Nucleic acids research 2012; 41: D597-D604.

Holmes LA, Turner A, Thompson RC. Adsorption of trace metals to plastic resin pellets in the marine environment. Environmental Pollution 2012; 160: 42-48.

Huang W, Song B, Liang J, Niu Q, Zeng G, Shen M, et al. Microplastics and associated contaminants in the aquatic environment: A review on their ecotoxicological effects, trophic transfer, and potential impacts to human health. Journal of Hazardous Materials 2020: 124187.

Kelly S, Grenyer R, Scotland RW. Phylogenetic trees do not reliably predict feature diversity. Diversity and Distributions 2014; 20: 600-612.

Kettner MT, Oberbeckmann S, Labrenz M, Grossart H-P. The eukaryotic life on microplastics in brackish ecosystems. Frontiers in microbiology 2019; 10: 538.

Khalid N, Aqeel M, Noman A, Hashem M, Mostafa YS, Alhaithloul HAS, et al. Linking effects of microplastics to ecological impacts in marine environments. Chemosphere 2020: 128541. 
Kirstein IV, Wichels A, Krohne G, Gerdts G. Mature biofilm communities on synthetic polymers in seawater-Specific or general? Marine Environmental Research 2018; 142: 147-154.

Klöckner P, Reemtsma T, Wagner S. The diverse metal composition of plastic items and its implications. Science of The Total Environment 2020: 142870.

Law KL. Plastics in the marine environment. Annual review of marine science 2017; 9: 205-229.

Lawes JC, Neilan BA, Brown MV, Clark GF, Johnston EL. Elevated nutrients change bacterial community composition and connectivity: high throughput sequencing of young marine biofilms. Biofouling 2016; 32: 57-69.

Layglon N, Misson B, Durieu G, Coclet C, d'Onofrio S, Dang DH, et al. Longterm monitoring emphasizes impacts of the dredging on dissolved $\mathrm{Cu}$ and $\mathrm{Pb}$ contamination along with ultraplankton distribution and structure in Toulon Bay (NW Mediterranean Sea, France). Marine Pollution Bulletin 2020; 156: 111196.

Lee J-W, Nam J-H, Kim Y-H, Lee K-H, Lee D-H. Bacterial communities in the initial stage of marine biofilm formation on artificial surfaces. The journal of microbiology 2008; 46: 174-182.

Louis Y, Garnier C, Lenoble V, Omanović D, Mounier S, Pižeta I. Characterisation and modelling of marine dissolved organic matter interactions with major and trace cations. Marine Environmental Research 2009; 67: 100-107.

Luo W, Kelly SD, Kemner KM, Watson D, Zhou J, Jardine PM, et al. Sequestering uranium and technetium through co-precipitation with aluminum in a contaminated acidic environment. Environmental science \& technology 2009; 43: 7516-7522.

Mahapatra B, Dhal NK, Pradhan A, Panda BP. Application of bacterial extracellular polymeric substances for detoxification of heavy metals from contaminated environment: A mini-review. Materials Today: Proceedings 2020; 30: 283-288.

Mahé F, Rognes T, Quince C, de Vargas C, Dunthorn M. Swarm: robust and fast clustering method for amplicon-based studies. PeerJ 2014; 2: e593.

Mao R, Lang $\mathrm{M}$, Yu X, Wu R, Yang X, Guo X. Aging mechanism of microplastics with UV irradiation and its effects on the adsorption of heavy metals. Journal of Hazardous Materials 2020: 122515.

Mazoyer C, Vanneste H, Dufresne C, Ourmières Y, Magaldi MG, Molcard A. Impact of wind-driven circulation on contaminant dispersion in a semi-enclosed bay. Estuarine, Coastal and Shelf Science 2020; 233: 106529.

Misson B, Garnier C, Lauga B, Dang DH, Ghiglione J-F, Mullot J-U, et al. Chemical multi-contamination drives benthic prokaryotic diversity in the anthropized Toulon Bay. Science of the Total Environment 2016; 556: 319-329.

Mitbavkar S, Anil AC. Seasonal variations in the fouling diatom community structure from a monsoon influenced tropical estuary. Biofouling 2008; 24: 415426.

Molino PJ, Wetherbee R. The biology of biofouling diatoms and their role in the development of microbial slimes. Biofouling 2008; 24: 365-379.

Muthukrishnan T, Dobretsov S, De Stefano M, Abed RM, Kidd B, Finnie AA. Diatom communities on commercial biocidal fouling control coatings after one year of immersion in the marine environment. Marine environmental research 2017; 129: 102-112. 
Oberbeckmann S, Kreikemeyer B, Labrenz M. Environmental Factors Support the Formation of Specific Bacterial Assemblages on Microplastics. Frontiers in Microbiology 2018; 8.

Oberbeckmann S, Osborn AM, Duhaime MB. Microbes on a bottle: substrate, season and geography influence community composition of microbes colonizing marine plastic debris. PLoS One 2016; 11: e0159289.

Parada AE, Needham DM, Fuhrman JA. Every base matters: assessing small subunit rRNA primers for marine microbiomes with mock communities, time series and global field samples. Environmental microbiology 2016; 18: 1403-1414.

Patil JS, Anil AC. Biofilm diatom community structure: influence of temporal and substratum variability. Biofouling 2005; 21: 189-206.

Pinto M, Langer TM, Hüffer T, Hofmann T, Herndl GJ. The composition of bacterial communities associated with plastic biofilms differs between different polymers and stages of biofilm succession. PloS one 2019; 14: e0217165.

Polst BH, Anlanger C, Risse-Buhl U, Larras F, Hein T, Weitere M, et al. Hydrodynamics alter the tolerance of autotrophic biofilm communities toward herbicides. Frontiers in microbiology 2018; 9: 2884.

Pringault $\mathrm{O}$, Viret $\mathrm{H}$, Duran R. Interactions between $\mathrm{Zn}$ and bacteria in marine tropical coastal sediments. Environmental Science and Pollution Research 2012; 19: 879-892.

Richard H, Carpenter EJ, Komada T, Palmer PT, Rochman CM. Biofilm facilitates metal accumulation onto microplastics in estuarine waters. Science of the total environment 2019; 683: 600-608.

Rivera S, Vasselon V, Jacquet S, Bouchez A, Ariztegui D, Rimet F. Metabarcoding of lake benthic diatoms: from structure assemblages to ecological assessment. Hydrobiologia 2018; 807: 37-51.

Rognes T, Flouri T, Nichols B, Quince C, Mahé F. VSEARCH: a versatile open source tool for metagenomics. PeerJ 2016; 4: e2584.

Sabater S, Guasch H, Ricart M, Romaní A, Vidal G, Klünder C, et al. Monitoring the effect of chemicals on biological communities. The biofilm as an interface. Analytical and bioanalytical chemistry 2007; 387: 1425-1434.

Tesán Onrubia JA, Djaoudi K, Borgogno F, Canuto S, Angeletti B, Besio G, et al. Quantification of Microplastics in North-Western Mediterranean Harbors: Seasonality and Biofilm-Related Metallic Contaminants. Journal of Marine Science and Engineering 2021; 9: 337.

Tessier E, Garnier C, Mullot J-U, Lenoble V, Arnaud M, Raynaud M, et al. Study of the spatial and historical distribution of sediment inorganic contamination in the Toulon bay (France). Marine Pollution Bulletin 2011; 62: 2075-2086.

Tien C-J, Chen CS. Patterns of metal accumulation by natural river biofilms during their growth and seasonal succession. Archives of environmental contamination and toxicology 2013; 64: 605-616.

Tlili A, Berard A, Blanck H, Bouchez A, Cássio F, Eriksson KM, et al. Pollution induced community tolerance (PICT): towards an ecologically relevant risk assessment of chemicals in aquatic systems. Freshwater Biology 2016; 61: 2141-2151.

Turner A, Holmes LA. Adsorption of trace metals by microplastic pellets in fresh water. Environmental Chemistry 2015; 12: 600-610.

Vasselon V, Rimet F, Tapolczai K, Bouchez A. Assessing ecological status with diatoms DNA metabarcoding: Scaling-up on a WFD monitoring network (Mayotte island, France). Ecological Indicators 2017; 82: 1-12. 
Wang Y, Wang X, Li Y, Li J, Wang F, Xia S, et al. Biofilm alters tetracycline and copper adsorption behaviors onto polyethylene microplastics. Chemical Engineering Journal 2020; 392: 123808.

Wong $\mathrm{KH}$, Obata $\mathrm{H}$, Kim T, Mashio AS, Fukuda H, Ogawa H. Organic complexation of copper in estuarine waters: An assessment of the multi-detection window approach. Marine Chemistry 2018; 204: 144-151.

Wright RJ, Erni-Cassola G, Zadjelovic V, Latva M, Christie-Oleza JA. Marine plastic debris: A new surface for microbial colonization. Environmental Science \& Technology 2020; 54: 11657-11672.

Zargiel KA, Swain GW. Static vs dynamic settlement and adhesion of diatoms to ship hull coatings. Biofouling 2014; 30: 115-129.

Zettler ER, Mincer TJ, Amaral-Zettler LA. Life in the "plastisphere": microbial communities on plastic marine debris. Environmental science \& technology 2013; 47: 7137-7146.

Zhang W, Ding W, Li Y-X, Tam C, Bougouffa S, Wang R, et al. Marine biofilms constitute a bank of hidden microbial diversity and functional potential. Nature communications 2019; 10: 1-10.

Zou J, Liu X, Zhang D, Yuan X. Adsorption of three bivalent metals by four chemical distinct microplastics. Chemosphere 2020; 248: 126064. 